\title{
3D DOCUMENTATION AND DATA MANAGEMENT IN THE DAZU THOUSAND-HAND BODHISATTVA STATUE IN CHINA
}

\author{
M.L. Hou ${ }^{\text {a, } * \text {, Y.G. Hu }}{ }^{\text {a }}$, and Y.H. Wu ${ }^{\text {c }}$, X.S. Zhao ${ }^{\text {b }}$ \\ a School of Geomatics and Urban Information, Beijing University of Civil Engineering and Architecture, Zhanlanguan Road, \\ Xicheng District, Beijing, 100044,China-(houmiaole@163.com, huyungang@bucea.edu.cn) \\ ${ }^{\mathrm{b}}$ School of Geomatics and Urban Information, China University of Mining Technology, Xueyuan Road ,Haidian District, Beijing \\ 100083, China-zxs@cumtb.edu.cn \\ ${ }^{\mathrm{c}}$ Historic Cultural Research Institute, No.2 Gaoyuan Street, Chaoyang District, Beijing, 100029, China-wuyuhua@cach.org.cn
}

Commission VI, WG VI/4

KEY WORDS: Cultural Heritage; 3D Documentation, 3D Information Application

\begin{abstract}
:
Recently different types 3D data of many cultural heritage are collected, however, how to store and manage these data problem. This paper presents a new solution regarding cultural 3D information fine reconstruction and data management based on 3D modeling. These data were stored with the file system and database, which improved the efficiency of data retrieval; on this basis, hyper-fine 3D models of cultural relics were established. Fine 3D information model based on this method can be used for 3D statistics, virtual restoration and change detection, etc. It can provide a scientific basis for the field of conservation and restoration of cultural relics, but can also provide a reference for fine 3D reconstruction to be applied to other cultural relics. Finally, the Dazu Thousand-hand Bodhisattva has been taken as an example, which verified the feasibility and effectiveness of the program.
\end{abstract}

\section{INTRODUCTION}

The Dazu Thousand-hand Bodhisattva Statue is China's largest three-dimensional cliff-carved statue, combining sculpture, clay sculpture, gold foil painting, and colored drawing(Wu et al, 2011). Its standing height is about $7.7 \mathrm{~m}$, and the width is about $10.9 \mathrm{~m}$; the frontal projected area is about $84 \mathrm{~m}^{2}$ and the total curved surface area exceeds $210 \mathrm{~m}^{2}$. The major Bodhisattva statue in the center is carved with a thousand hands holding different dharma-vessels, and is known as "the world treasury of stone-carving art" (Tian et al, 2010). It is of highly historical, scientific, and artistic value. Currently, the Dazu Thousand-hand Bodhisattva Statue looks well on the whole, but local destruction is very serious. Therefore, it is of great significance to document its present situation.

Over the years, the efforts to record the Dazu Thousand-hand Bodhisattva Statue can be divided into two categories: one is the surveying and mapping of its basic morphology, and the other is image recording. The surveying and mapping of its basic morphology involves traditional tape measurement, level measurement, optical close-range photogrammetry ,total station measurement, and digital close-range photogrammetry; image recording includes sketching, traditional film photography (black \& white and color photography), digital photography, and DV recording (Hu et al, 2008; Zhang et al, 2007; Li, 1998). However, the 3D carved statue of the Thousand-hand Bodhisattva is complex in structure, so its morphology, structure and preservation condition cannot be completely or realistically reflected by plane and facade surveying and mapping, given the following limitations: information retention is neither complete nor realistic; the failure to perform disease investigation, quantitative statistics and assessment of high precision; the failure to provide accurate data for protection and preservation; the failure to provide reliable basis for restoration or virtual rehabilitation. Recent advances in terrestrial laser scanning technology allow us the fast and efficient collection of 3D coordinates of cultural heritage object, automatically (Yastikli, 2007). Different techniques and principles are used to determine the 3D coordinates of cultural heritage objects using terrestrial laser scanning systems. In the phase comparison method, the transmitted laser beam is modulated by a harmonic wave, and the distance is then calculated based on the phase difference between the transmitted and received wave (Pieraccini et al, 2001; Blais, 2004). Triangulation scanners are based on the optical triangulation method. The transmitting device sends a laser beam to the surface of object and the CCD camera detects the laser beam at the other end of the base. A 3D coordinate of laser beam on the object's surface is derived from the resulting triangle. The scanning system based on the triangulation method is another system allows measurement up to a few meters, and can achieve accuracy within a few micrometers (Fontana et al, 2002). The triangulation scanner systems are suitable for precise scanning, such as sculptures in cultural heritage documentation (Fowles et al, 2003).

However, with the continuous improvement of the 3D data processing function, data formats continuously vary and the relationship between the data becomes more and more complex; at the same time, the data resolution continues to improve, leading to an increasing amount of $3 \mathrm{D}$ information data. Therefore, the question of how to manage multi-source mass data in engineering, both scientifically and effectively, and how to improve the safety of data and convenience of query data have become key issues in urgent need of a solution in current cultural relic 3D information management. The primary objective of this paper is to investigate the basic procedure and applications for fine $3 \mathrm{D}$ reconstruction and

\footnotetext{
* Corresponding author
} 
data management for documentation of cultural heritage. The following Section 2 will introduce the key procedure of 3D information documentation of cultural relics, providing the technical information specific to new methods regarding documentation processes in order to explain methodology and the most suitable approach, from data acquisition to the final product. And the 3D information data management is presented in Section 3, which presents a useful method of combining the file system with database management to store 3D information of the Dazu Thousand-hand Bodhisattva. Several applications are discussed, and the technical aspects of new methods used for cultural heritage documentation are assessed.

\section{CULTURAL RELIC 3D INFORMATION DOCUMENTATION}

\subsection{Overall Process}

The basic procedure and application for fine 3D information Documentation of cultural relics is shown in Figure 1.

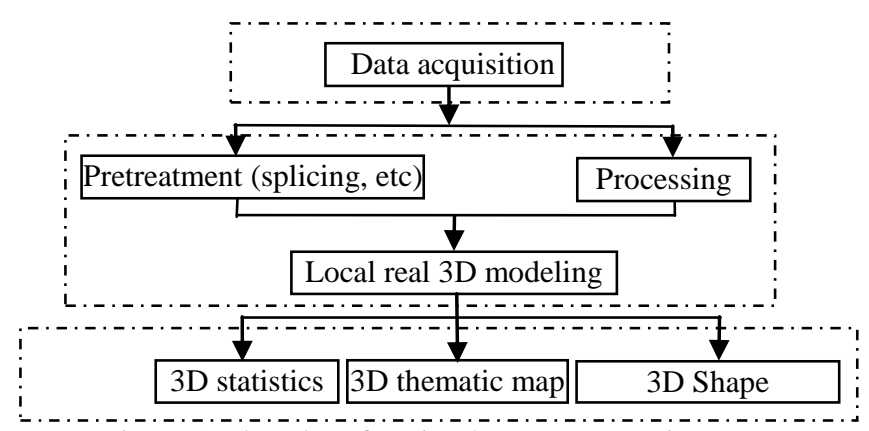

Figure 1. Flowchart for Fine 3D Documentation

\subsection{High-precision 3D Documentation}

The investigation involving the documentation of the Dazu Thousand-hand Bodhisattva Statue was attempted by the Beijing University of Civil Engineering and Architecture, the Beijing Digsur Company, and the Chinese Historic Cultural Research Institute in 2010.The scanning surveys were performed with Romer/CimCore from Hexagon (shown in Figure 2). After data acquisition, all scans were registered onto the reference coordinate system using reflectors in the scan area and measurement coordinates with $0.01 \mathrm{~mm}$ accuracy.

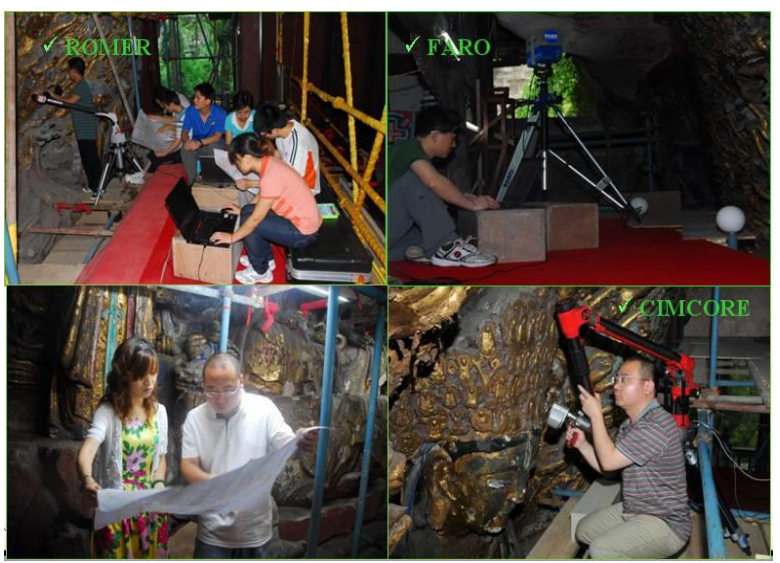

Figure 2. Data Acquisition Using CimCore
In this paper, the Dazu Thousand-hand Bodhisattva Statue has been taken as the research object, using the Romer/CimCore high precision scanner to collect data , and the data amounted to 380G. The holistic data of the Dazu Thousand-hand Bodhisattva Statue is shown in Figure 3.

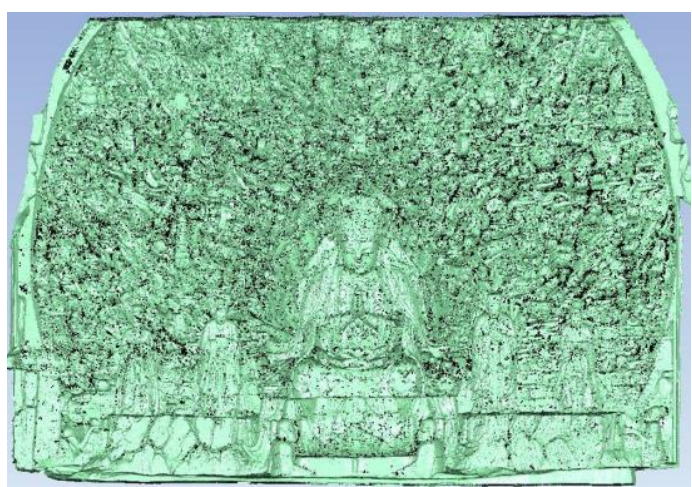

Figure 3. The 3D Cloud Data of The Dazu Thousand-hand Bodhisattva Statue

\subsection{D Fine Modeling}

Based on the fine 3D cloud points from the Romer/CimCore scanner, the fine real 3D model of the Dazu Thousand-hand Bodhisattva Statue can be constructed, which has the real size and texture. It can be used to make facade and profile maps, which can be directly used in AutoCAD to measure its size, and to extract the real data information. Thus, the Dazu Thousand-hand Bodhisattva Statue can be completely and permanently preserved in its current condition. Figure 4 shows the different models of the Dazu Thousand-hand Bodhisattva Statue.

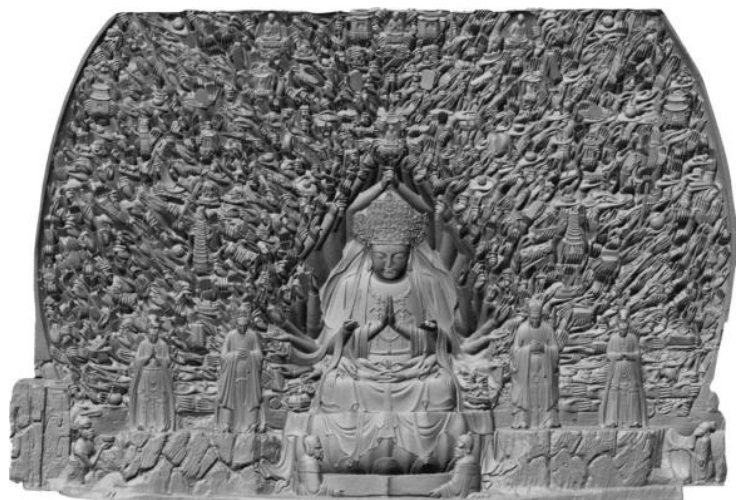

Figure 4. 3D Model The Dazu Thousand-hand Bodhisattva Statue

\section{CULTURAL RELIC 3D INFORMATION MANAGEMENT}

The data types involved in 3D information documentation include texture data, point cloud data, model data, real 3D model data, Digital Orthophoto Map, DLG, section plans, and a large number of spatial data are all processed with commercial software that the point cloud data algorithm more mature. Therefore, in order to preserve the high data processing efficiency, ensure data security and integrity, and the sustainable use of result data after data processing, such as $3 \mathrm{D}$ display and the raw data archive, so the spatial data in the research still need to use file management, while the 
relationship between the data will use the relational database to store and manage, because it not only can store the relationship between the space data, but can improve the cross-query efficiency of spatial data in the project with the relational database.

\subsection{The 3D Information Data Management System}

In file management mode, the various data will be stored according to their classification. Attribute data and the relation of spatial data are stored in the relational database, which can perform some operations for data in the general database management system, such as insert, edit, and delete. Even pointers in the database can point to the spatial data in the file system, which can call and display the spatial data in the file system without the need to open the data from the file system, thereby improving the efficiency of data query and display. Figure 5 shows the data management system architecture in this research design.

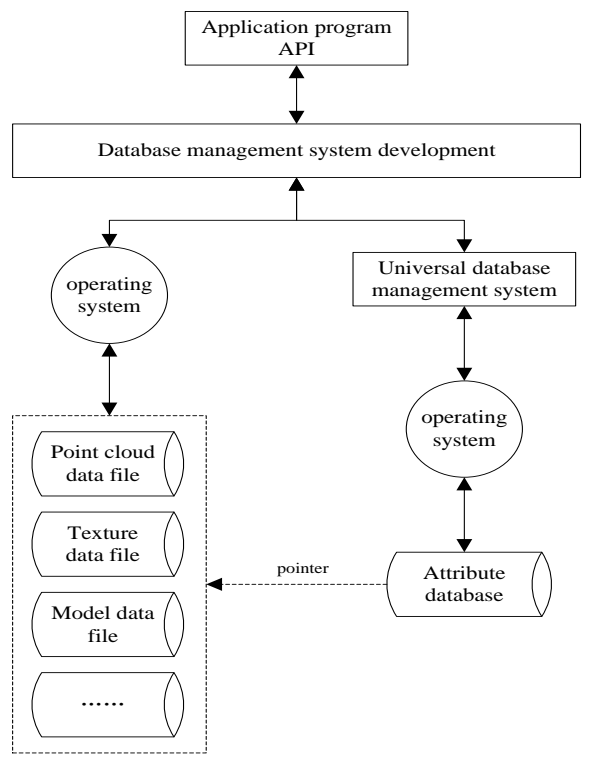

Figure 5. Data Management System Framework Diagram

\subsection{The 3D Information File Management}

All types of spatial data are managed using files in the cultural relic 3D information documentation project. Given the many types of spatial data, and the amount of data in the project, the appropriate storage structure of the data in the file management mode needs to be organized and developed, which can facilitate the spatial data management, but can also provide convenient database management.

The Thousand-hand Bodhisattva 3D information is comprised of some raw data, such as texture data, point cloud data, model data and real 3D model data, and also produced Orthophoto Map, DLG and section plans. Therefore, file management for the Thousand-hand Bodhisattva 3D information documentation project should clear the collection range partitioning and engineering object of the cultural relic, according to directory structure of the cultural relic 3D information documentation, and tidy various types of data in acquisition and processing. In this study, the file management structure of 3D information data is shown in Figure 6, according to the characteristics of the Thousandhand Bodhisattva $3 \mathrm{D}$ information documentation project.

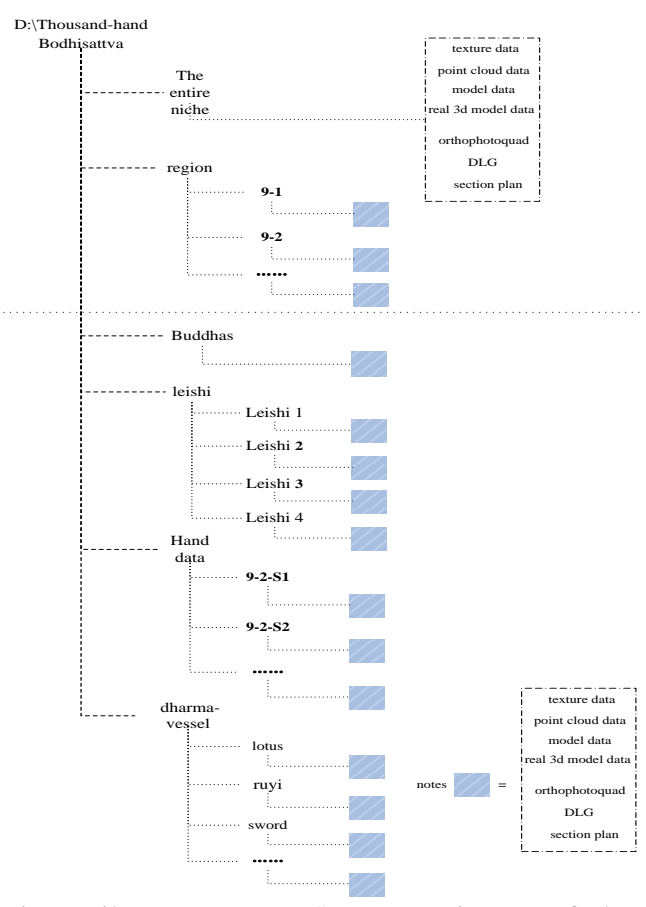

Fig.6. File Management Structure Diagram of The Thousand-hand Bodhisattva

\section{CULTURAL RELIC 3D INFORMATION APPLICATION}

\subsection{D Statistics}

Can you guess how many hands there are in the Dazu Thousand-hand Bodhisattva statue? According to the historic record, there were exactly 1000 hands at the beginning, which is why it was called the Thousand-hand Bodhisattva. Currently, according to the 3D model and the details, there are only 830 hands in the holistic Dazu Thousand-hand Bodhisattva statue.

The restoration project needed the data from the restoration work area in 2013. Based on the fine 3D model, several statistics could be processed, as Figure 7 shows. The total restoration area in 2013 was $38.08 \mathrm{~m}^{2}$. The colorful paint area of hand-held instruments is $2.98 \mathrm{~m}^{2}$, and the gold foil area is $35.1 \mathrm{~m}^{2}$.

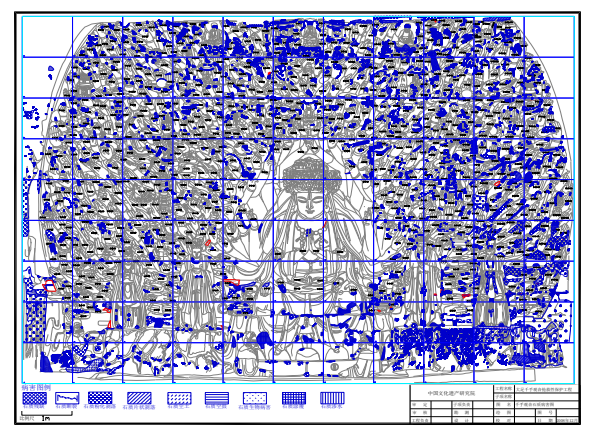

Figure 7. The Disease Area in 2013

\subsection{Division Characteristic}

Based on the fine 3D model, 3D thematic maps can be used to produce: Orthophoto Map, digital line graph, and contour map. And space characteristic can be analyzed. According to 
the hand direction and the carving technical the whole stature can be divided into 13 areas.

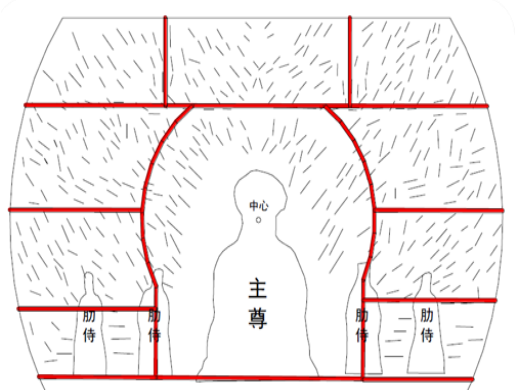

Figure 8. There Are 13 Areas in The Whole Stature

\subsection{D Shape Virtual Restoration}

For the purpose of aiding archaeological studies and cultural relic protection projects, 3D shape virtual restoration is vital. The real restoration effect could be evaluated by comparing it with the virtual restoration effect. Figure 9 shows the effects of virtual restoration of the whole stature.

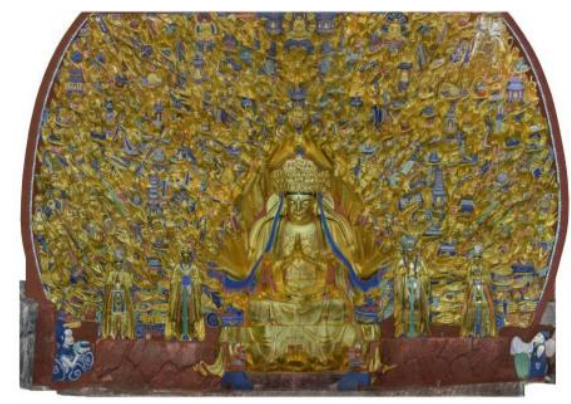

Figure 9. The Effect of Virtual Restoration

\section{CONCLUSION}

This paper discusses key technologies and related applications of 3D documentation and the management of cultural relics. The work was as follows: (1) Cultural relic 3D information data were managed by the way of a combination database and file system; the program could provide a new approach for the data management in the protection work of cultural relics. (2) Detailed information documentation of the whole niche statues was achieved, which could be taken as a permanent archive of historical data. (3) 3D fine models of all objects of the Thousand-hand Bodhisattva were established, which could provide basic data for virtual restoration or digital display and other follow-up applications. (4) According to the 3D fine model, accurate calculation of basic data could be carried out, which could provide basic information (the area, volume, and damaging rate) and related maps for actual restoration work. (5) Based on the 3D fine model, the virtual restoration of the Thousand-hand Bodhisattva was completed, which could provide a reliable reference for actual restoration.

Aimed at the problem of large numbers of multi-source data appearing in the 3D information collection process of cultural relics, this paper proposes a method of combining file systems and database management to store the 3D information from the Dazu Thousand-hand Bodhisattva, which improved the query efficiency of 3D information data; however, it was not completely suitable for other purposes or different application engineering. Therefore, the follow-up work, combined with data characteristics of cultural relic protection, with concentrate on the research of the universality of data management in the protection of cultural relics, which has an important significance for the data management in the field of protection cultural relics.

\section{ACKNOWLEDGMENT}

The work described in this paper was substantially supported by an award from the National Basic Research Program of China (973 Program, under grant No. 2012cb725301) and Natural Science Foundation Program (under grant No. 8111003). This work was also supported by a grant from the National Natural Science Foundation of China (No. 41171304). The authors would like to acknowledge and thank the Dazu Museum for their support of this work. The authors also would like to thank Prof. Changfa Zhan for his novel suggestions. Thanks to Fangyin Li and Huili Chen for their work on the capturing and processing of the data.

\section{REFERENCES}

Blais F., 2004. Review of 20 years of range sensors, Journal of Electronic Imaging. 13, pp.231-243.

Fontana R., Greco M., Materazzi M., Pampaloni E., Pezzati L., Rocchini C., Scopigno R., 2002. Three-dimensional modelling of statues: theMinerva of Arezzo, Journal of Cultural Heritage, 3(4), pp.325-331.

Fowles P.S., Larson J.H., Dean C., Solajic M., 2003. The laser recording and virtual restoration of a wooden sculpture of Buddha, Journal of Cultural Heritage, 4, pp.367-371.

Hu D.B., Xue T.N., Wang J.H., 2008. Zhang Gongyan. Analysis of Gold-covered Material of The Dazu Thousandhand Bodhisattva Statue in Baoding Mountain, Dazu, Chongqing. Sciences of Conservation and Archaeology, 20(3), pp.44-51.

Li F.Y.,1998. The Art of Dazu Grott. Chongqing, Chongqing Publisher, pp. 138.

Pieraccini M., Guidi G., Attzeni C., 2001. 3D digitizing of cultural heritage, Journal of Cultural Heritage, 2, pp.63-70.

Tian X.L., Li Z.L., Ma Q.L., 2010. Explore the Reason for Discoloration of the Gold Foil Surface of Chongqing Dazu Bodhisattva. Rare Metal Materials and Engineering, 39(Supplement 1),pp.311-315.

Wu Y.H., Hou M.L., Zhang Y.M., 2011. Application Progress and Direction of 3D Laser Scanning Technology in Geotechnical Cultural Relic Protection. Geomatics World, 9(2), pp.53-57.

Yastikli N., 2007. Documentation of cultural heritage using digital photogrammetry and laser scanning. Journal of Cultural Heritage, 8, pp.423-427.

Zhang R., Luo Y.L., Zhou M.Q., Zhu X., Wu Y.H., 2007. Key Technology for Cultural Relics Digitalization. Journal of Beijing Normal University, 43(2), pp.150-153. 